\title{
Effects of cooling in infant rats on growth, maturation, sleep patterns and responses to food deprivation
}

\author{
BY HEIDI H. SWANSON, ERIC BOLWERK AND ELI BRENNER \\ Netherlands Institute for Brain Research, Ijdijk 28, 1095KJ Amsterdam, The Netherlands
}

(Received 4 July 1983 - Accepted 31 January 1984)

\begin{abstract}
1. The confounding effects of undernourishment and body cooling, resulting from maternal separation, were investigated by separating food and warmth deprivation. Rat pups aged 3-16 d were deprived of food for alternate 24-h periods by removal from the lactating mother. Some of the pups were placed with a foster mother, who kept them warm, whereas others were put in an empty cage at $22^{\circ}$ which resulted in a sharp drop in body temperature.

2. Pups which were kept warm showed great fluctuations in weight between periods of starvation and feeding. The cooled pups lost less weight during deprivation but also recovered less on refeeding.

3. The resultant growth rate was much lower in non-fostered (i.e. cooled) than in fostered pups.

4. Up to the age of $8 \mathrm{~d}$, cooled pups failed to raise their body temperature above that of the surroundings and did not digest the milk in their stomachs. Although, thereafter, they were able to raise their temperature to $26^{\circ}$ and to digest stomach contents, the extra energy expended resulted in more severe growth restriction.

5. One-third of the pups died at $16 \mathrm{~d}$ but the rest were quickly rehabilitated by $a d$ lib. feeding and showed a normal growth rate, although they remained smaller than the controls.

6. The development of nipples, hair, eye opening and vaginal opening was related more to chronological age than to weight.

7. A side effect of cooling was an almost complete abolition of active (REM) sleep, which is normally very high in infants; a slight rebound increase in active sleep was seen at $21 \mathrm{~d}$. Direct as well as side effects of cooling may thus be responsible for some of the observed consequences of maternal separation.
\end{abstract}

In studies on the effects of early undernutrition on later somatic and behavioural development, there is often confusion between nutritional deficiency and deprivation of maternal care (Plaut, 1970; Smart, 1983). Many methods have been used to attempt to separate these two effects, such as reducing the mother's food supply (Smart \& Preece, 1973), increasing the number of pups in a litter (Kennedy, 1957; Widdowson \& Kennedy, 1962), or alternating pups between a lactating dam and a foster mother who has either been sensitized to infants (Slob et al. 1973) or whose nipples have been ligated after delivering her own litter (Lynch, 1976; Swanson et al. 1983). A complete elimination of the maternal care factor is impossible since one cannot control differences in behaviour of females towards well-fed and undernourished pups (Smart, 1983). An immediate consequence of removing the mother is infant cooling because the pups cannot keep up their body temperature before the age of approximately 9-11 d (Adolph, 1957; Taylor, 1960). Thus one of the functions of a foster mother is to keep the pups warm.

In a previous experiment on induction of maternal behaviour in virgin females, it was observed that pups aged 2-8 d, which were not gathered into a nest and covered by the foster mother's body, rapidly cooled to approximately room temperature. Under these circumstances the milk which they had taken in during the previous $24 \mathrm{~h}$ with a lactating mother was not digested and could still be seen through the body wall the following morning, whereas pups which had been kept warm had empty stomachs. Moreover, the cooled pups gained less weight than those whose body temperature had been kept up. The present experiment is a systematic investigation of the differential effects of nutritional deprivation and cooling on growth and maturation. An attempt will be made to answer the question of whether the consequences of maternal separation are due mainly to deprivation of food or to deprivation of warmth. Because cooling is known to suppress 
active (REM) sleep (Schmidek et al. 1972) which is normally very high in infants (Jouvet-Mounier et al. 1969; Gramsbergen et al. 1970; Mirmiran et al. 1981), the development of sleep patterns and some possible behavioural consequences of their disturbance were also examined.

\section{METHODS}

Nine litters of pups delivered from Wistar females were mixed and redistributed to the nine mothers so that each mother received four males and four females. When the pups were 3-d-old they were assigned to four experimental groups. Standard macrolon cages $(350 \times 230 \times 150 \mathrm{~mm})$ were used and were kept in the experimental room at a temperature of $22^{\circ}$, with white lights on from 7.00 to 19.00 hours.

\section{Controls (group l)}

\section{Experimental design}

Eight pups in each of three cages remained with their assigned lactating mother continuously. Sawdust and nesting material were present. The pups were weighed daily as a group in order to minimize handling.

\section{Fostered, warm (group 2)}

On day 3, four pups (two males and two females) were removed from each of three lactating mothers and placed into a similar cage containing a foster mother, who was also provided with nesting material. The following day (and every day thereafter until day 16) the four pups were removed from the foster mother and weighed as a group. They were then returned to the lactating mother. At the same time the four pups who had been with the lactating mother were removed, weighed together and given to the foster mother. The same eight pups (four males and four females) were alternated between the same two females (one lactating and one foster).

Foster mothers were previously prepared by exposing virgin females to pups for $6-8 \mathrm{~d}$. Most females became sensitized and showed maternal behaviour, which consisted of building a nest, gathering the pups into the nest, licking them and assuming a nursing position which resulted in the infants being kept warm (Rosenblatt, 1967). The pups could not be fed, of course, as the females were not lactating. Once a female became maternal she continued to show this behaviour.

\section{Non-fostered, cooled (group 3)}

On day 3, four pups (two males and two females) were removed from each of three lactating mothers and placed in the four corners of an empty cage. Sawdust was supplied but no other nesting material. The following day (and every day thereafter until day 16) the four infants were removed from the empty cage, weighed as a group and returned to their assigned mother. At the same time the four pups who had been with the lactating mother were weighed and placed in the empty cage.

\section{Additional controls (group 4)}

The lactating females in groups 2 and 3 had only four pups at a time whereas the control mothers from group 1 had eight pups all the time. Since litter size is known to affect growth (Kennedy, 1957; Park \& Nowosielski-Slepowron, 1971; Nowosielski-Slepowron \& Park, 1974) an additional control group was established in which only four pups (two males and two females) were assigned to each of three mothers, and left with them continuously until day 30 .

From the age of $16-30 \mathrm{~d}$ all pups were allowed to stay continously with the lactating 
mothers, who then each had eight pups. The pups were marked for individual recognition and weighed at frequent intervals. At day 30 , six males and six females from experimental groups 1,2 and 3 (equally distributed between mothers) were weaned and placed in group cages until they reached $100 \mathrm{~d}$ of age, when open field tests were carried out.

\section{EXPERIMENTAL OBSERVATIONS}

Growth and development

Twice a week, the skin temperature of the pups was measured with a flexible probe thermocouple placed between the thigh and body wall. The leg was pressed tightly against the body and the temperature read directly from a scale. Representative samples were taken from each group, including pups which had been with the lactating female overnight and those which had been either with a foster mother or without a mother. When pups were removed from a lactating dam, they all had milk in their stomach, which could be clearly seen through the semi-transparent body wall. Some pups still had a full stomach after $24 \mathrm{~h}$ of food deprivation. A note was made daily of how many pups in each group had milk in their stomach.

A note was made of the day on which the following indices appeared in each group, (a) nipple development (females only; male rats do not have nipples), (b) beginning of hair growth (down), $(c)$ eye opening and $(d)$ vaginal opening as an index of sexual maturation in females; no simple external measure is available for males.

\section{Sleep patterns}

Eight randomly selected pups from each of the experimental groups 1,2 and 3 were tested for effects of early undernutrition and cooling on sleep. At the age of $21 \mathrm{~d}$, they were observed individually for $60 \mathrm{~min}$ after $1 \mathrm{~h}$ accommodation at $32^{\circ}$. Every $10 \mathrm{~s}$ the behavioural state of each animal was noted as active sleep (AS), wakefulness (AW) or quiet sleep (QS). Wakefulness was characterized by eyes open with or without locomotion. Active sleep could be recognized by jerky twitches of limbs, ears, vibrissae and tail and by shallow irregular breathing with eyes closed. The rest of the time was classified as quiet sleep.

Additional sleep observations. As a control for the acute effects of cooling on sleep patterns of very young rats, a group of 4-5-d-old, normal pups, continuously living with their mother was tested. Six pups were observed (two at a time) at an ambient temperature of $32^{\circ}$ after $10 \mathrm{~min}$ habituation and again 2 and $4 \mathrm{~h}$ later. Six more pups were similarly tested at an ambient temperature of $21^{\circ}$. Since eye opening had not yet occurred at this age, AW was characterized by gross coordinated movements.

\section{Open field test}

At $100 \mathrm{~d}$ of age, the animals were subjected to an open field test, a standard behavioural test concerned with emotionality and exploratory activity (Van de Poll et al. 1978), which has been shown to be responsive to early environmental influences (Swanson et al. 1983), as well as early AS deprivation (Mirmiran et al. 1983). The animals were tested for five consecutive days in a circular arena, according to a standard procedure (Swanson $e t$ al. 1983). Ambulation and rearing were noted, along with time spent grooming. Faecal boluses were counted after each of the 2 min tests.

\section{RESULTS}

\section{Body temperature}

Pups younger than $8 \mathrm{~d}$ were kept warm by their mother. When removed from the lactating female their skin temperature registered $31-32^{\circ}$. This applied both to pups continuously 


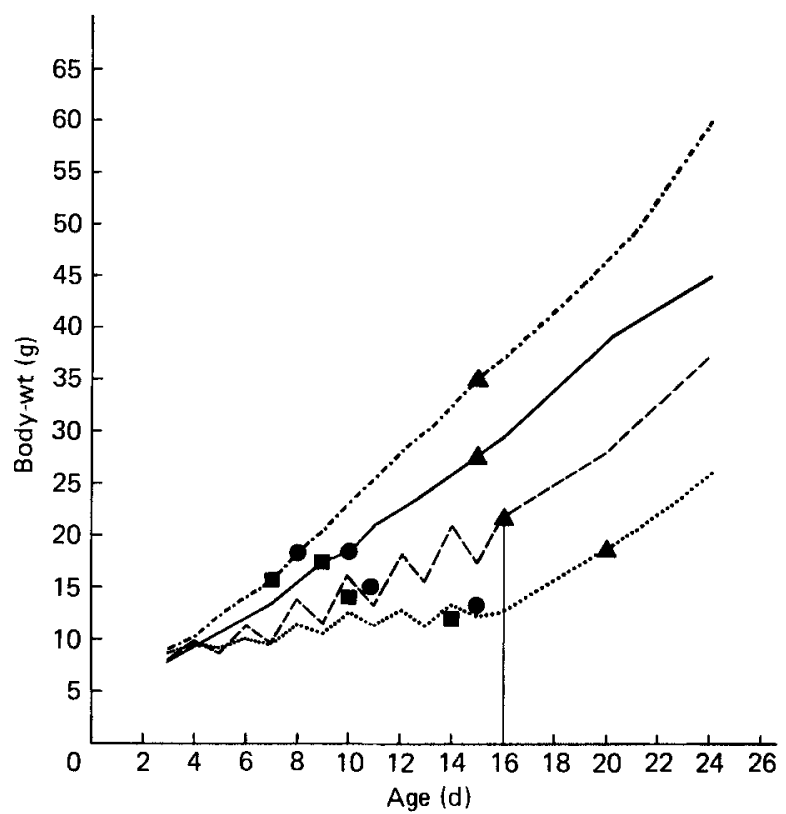

Fig. 1. Effects of litter size, and food and warmth deprivation on growth and maturation in rats. Median aged (d) at which: ( $\boldsymbol{\square})$, nipples become visible in females; $(\boldsymbol{O})$, hair appears; $(\boldsymbol{\Delta})$, eyes open. ( - ), Group 1 , controls (eight pups per litter); (---), group 2, food deprived, fostered; (..), group 3, food deprived, cooled; (-...), group 4, additional control (four pups per litter). There were twenty-four pups, distributed over three litters in each group. Pups from groups 2 and 3 were returned to the lactating mothers on day 16.

with their mother (group 1) or intermittently with their mother (groups 2 and 3). Nonlactating foster mothers (group 2) gathered the pups into the nest and kept them as warm as the lactating mothers kept their pups. In contrast, pups in a cage without a mother (group 3) were not able to maintain their body temperature and cooled off rapidly to room temperature $\left(22^{\circ}\right)$. Pups older than $8 \mathrm{~d}$ could maintain their temperature at $26-27^{\circ}$ after $24 \mathrm{~h}$ exposure to an ambient temperature of $22^{\circ}$.

\section{Milk digestion}

Pups removed from a lactating female always had milk in their stomachs. This was clearly visible as a white crescent through the semi-transparent abdominal wall. Pups deprived of food having been with a non-lactating foster mother for $24 \mathrm{~h}$ (group 2) had no milk in their stomachs. Before the age of $8 \mathrm{~d}$, pups without a mother (group 3) still had a full stomach but, after they reached the age of $8 \mathrm{~d}$, the milk was digested.

\section{Growth}

The growth rate (see Figs. 1 and 2) of control pups living continuously with a lactating female depended on the number of pups in the litter. Pups from litters of four (group 4) gained $2.3 \mathrm{~g} / \mathrm{d}$ whereas those from litters of eight (group 1) gained $1.6 \mathrm{~g} / \mathrm{d}$. The growth rate of experimental pups must be compared to that of those in control group 4, since the mother received only half of each litter, i.e. four pups were suckled at a time, while the remaining half were either with the foster mother or in a cage without a mother. After $24 \mathrm{~h}$ with a foster mother, pups from group 2 lost an average of $1.5 \mathrm{~g}$ each, representing $20 \%$ of their body-weight. On being returned to the lactating female for $24 \mathrm{~h}$, they regained $3.8 \mathrm{~g}$, 


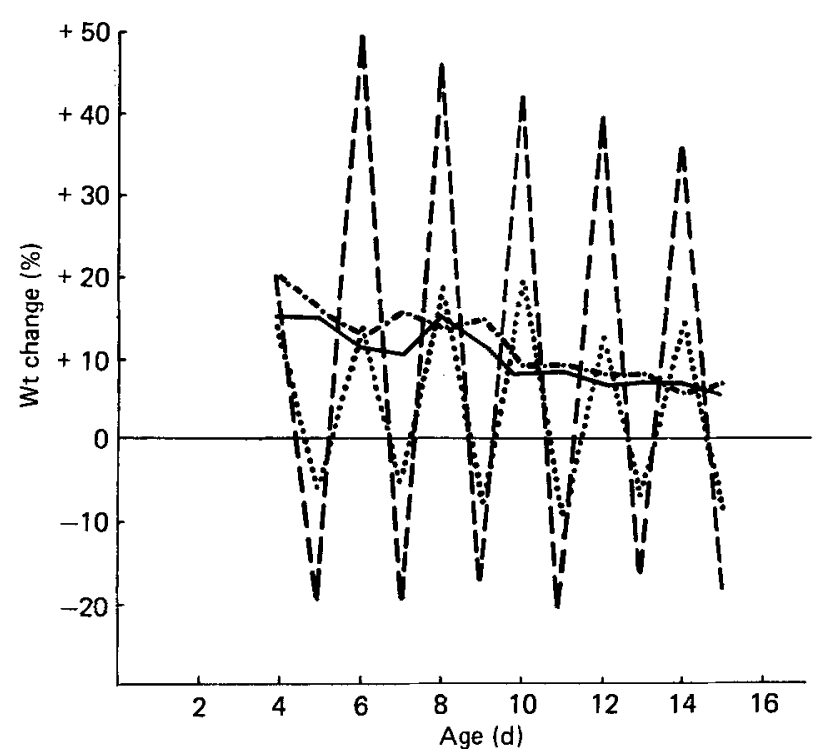

Fig. 2. Mean percentage weight change from previous day, after $24 \mathrm{~h}$ sucking (with mother; values above horizontal line) or $24 \mathrm{~h}$ food deprivation (without mother; values below horizontal line). (-), Group 1 , controls (eight pups per litter); (---), group 2, food deprived, fostered ; . . ), group 3, food deprived, cooled; (-..-), group 4, additional control (four pups per litter).

i.e. about $40 \%$ of their body-weight. Over $2 \mathrm{~d}$ they thus showed a net increase of $20 \%$. This percentage remained the same with increasing age with the result that daily weight fluctuations gradually increased to $-3.8 \mathrm{~g}$ and $+5.7 \mathrm{~g}$. Since the weight gained always exceeded the weight lost, there was a step-wise increase in weight, the mean forming a smooth curve.

Pups whose body temperature was allowed to drop (group 3) lost less weight in $24 \mathrm{~h}(0.6 \mathrm{~g}$ increasing to $1.0 \mathrm{~g}$ or approximately $7 \%$ ) than those who were kept warm by the foster mother. On the other hand, they also gained less weight $(1.5-2 \mathrm{~g}$ or $15 \%)$ after being returned to the lactating mother. The absolute, as well as the relative, rate of weight gain was therefore less in this group than in the fostered young. On day 8 , when the pups without a mother were able partly to raise their body temperature (to $26^{\circ}$ ), the absolute weight gain was further decreased. The pups looked progressively weaker and more debilitated. On day 16 , seven of the twenty-four pups were found dead, perhaps because they were too weak to suck. The weight range of the pups that died was the same as that of the survivors.

The final weight gain per pup from days 3-16 was $21.7 \mathrm{~g}$ in group $1(274 \%), 12.8 \mathrm{~g}$ in group $2(160 \%)$ and $4.4 \mathrm{~g}$ in group $3(54 \%)$. It thus seems that cooling, in connection with undernutrition, had a more drastic effect on growth than undernutrition alone since the cooled pups were not able to take full advantage of the refeeding periods. Both lactating and foster mothers immediately accepted either warm or cold infants, placing them in the nest and sitting over them in a nursing position.

After being returned to the lactating mothers full time (now eight pups per litter), both previously-fostered and previously-cooled pups gained weight rapidly, at a rate approximately equal to that of controls with eight pups (group 1). At day 30 (Table 1) there was a significant difference between all treatment groups but no sex difference. The treatment effects were still evident at day 100 in both sexes although differences between treatments were less. All animals appeared healthy and active. 
Table 1. Effect of cooling and food deprivation on growth and maturation of rat pups

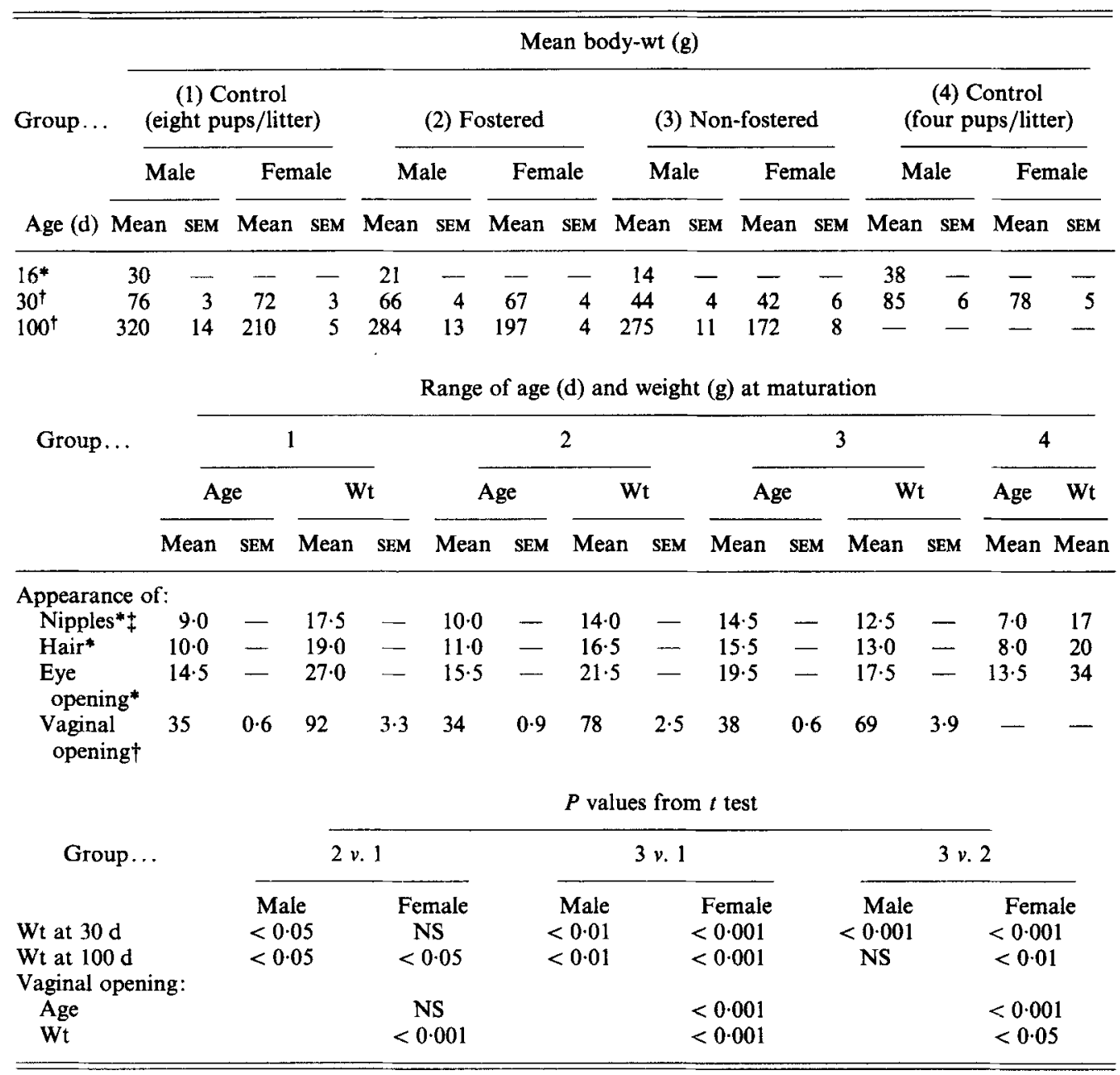

NS, not significant.

* Group observations (three groups).

$\dagger$ Individual observations ( $n$ 6).

$\ddagger$ Females only.

\section{Somatic maturation}

The age and corresponding weight at which various maturity indices became manifest are shown in Table 1 and Fig. 1. Nipples first appeared in control females when they weighed approximately $17 \mathrm{~g}$, which was day 7 in litters of four pups and day 9 in litters of eight pups. Fostered pups first showed nipple development on day 10, at an approximate weight of $14 \mathrm{~g}$, and cooled pups only on day 14 at an approximate weight of $12.5 \mathrm{~g}$. Similarly, down hair first appeared approximately $1 \mathrm{~d}$ after nipple development in all groups. The appearance of nipples as well as hair occurred at about the same time in all animals in a particular treatment group although there was a little more variation in the cooled group, where individual body-weights also covered a greater range. Eye opening showed a similar 


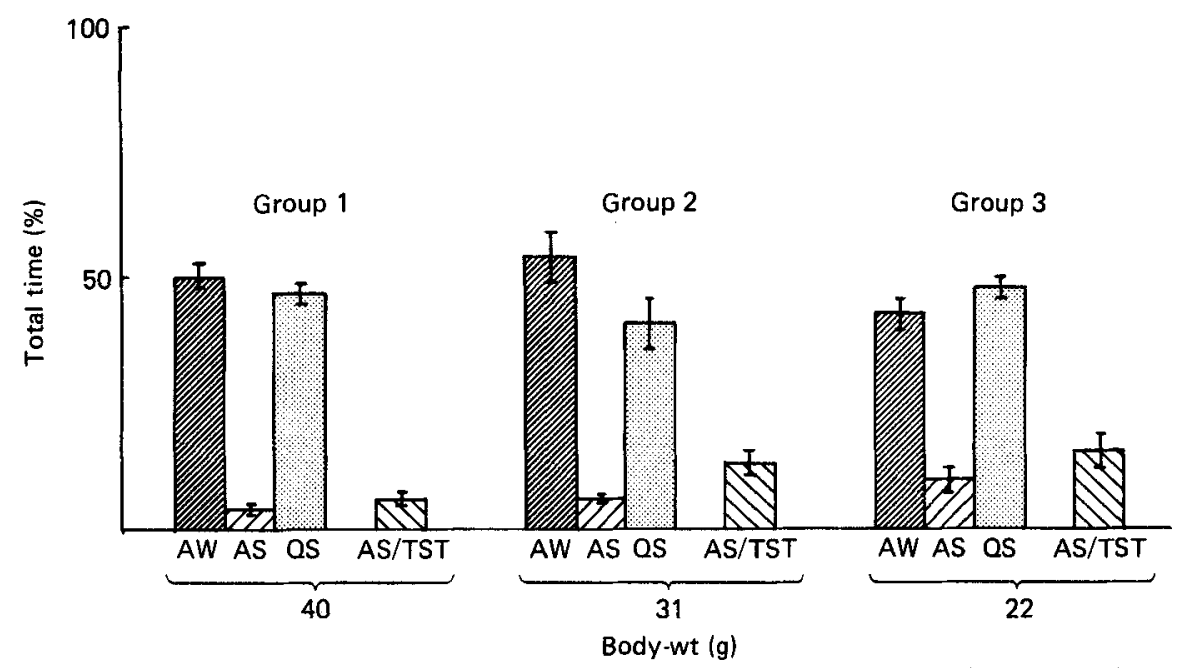

Fig. 3. Sleep patterns at 21 d measured at $32^{\circ}$. Group 1, controls; group 2, food deprived, fostered; group 3, food deprived, cooled. Means with standard errors of the mean represented by vertical bars for eight rats per group. AW, awake; AS, active sleep; QS, quiet sleep; expressed as percentage total time. AS/TST, active sleep/total sleep time.

pattern but more individual variability. These developmental stages seem partly related to age and partly to weight.

Sexual maturation, taking age at vaginal opening as an index, was significantly delayed in the cooled animals in comparison with either control or fostered animals but there was no difference between control and fostered animals. Weight at vaginal opening was, however, significantly lower in both fostered and non-fostered animals when compared with controls, suggesting that sexual maturation is primarily dependent on age, not weight.

\section{Sleep patterns}

Sleep patterns in 4-d-old pups in warm and cold environments. Under normal conditions in the nest, pups display AS most of the time, with brief periods (less than $10 \mathrm{~s}$ ) of AW, the rest of the time being spent in QS (Mirmiran et al. 1981). These findings were confirmed in the additional experiment in which normal pups, 4-5 d old, were observed after 2-h habituation at $32^{\circ}$. Active sleep/total sleep time (AS/TST) was $76 \%$. In contrast, after $2 \mathrm{~h}$ at $21^{\circ}$, there was almost complete abolition of AS, AS/TST being only $7 \%$. Most of the time the animals were torpid, interspersed by brief periods of AW.

Sleep patterns in experimental animals at 21 days. The incidence of AS was greater in fostered than in control pups and further increased in cooled pups (Fig. 3). Differences between treatment groups and controls, as well as between treatments, were significant ( $t$ test, $P<0.05$ ). At this age, the percentage AS was only 3-10\% in all groups, the rest of the time being divided about equally between $\mathrm{AW}$ and $\mathrm{QS}$. The differences in AS time between groups are accentuated when expressed as a percentage of total sleep time (AS/TST). An increase in AS can be interpreted as either a sign of immaturity (in view of the small size and delayed development of the animals) or a rebound effect after previous AS deprivation. 

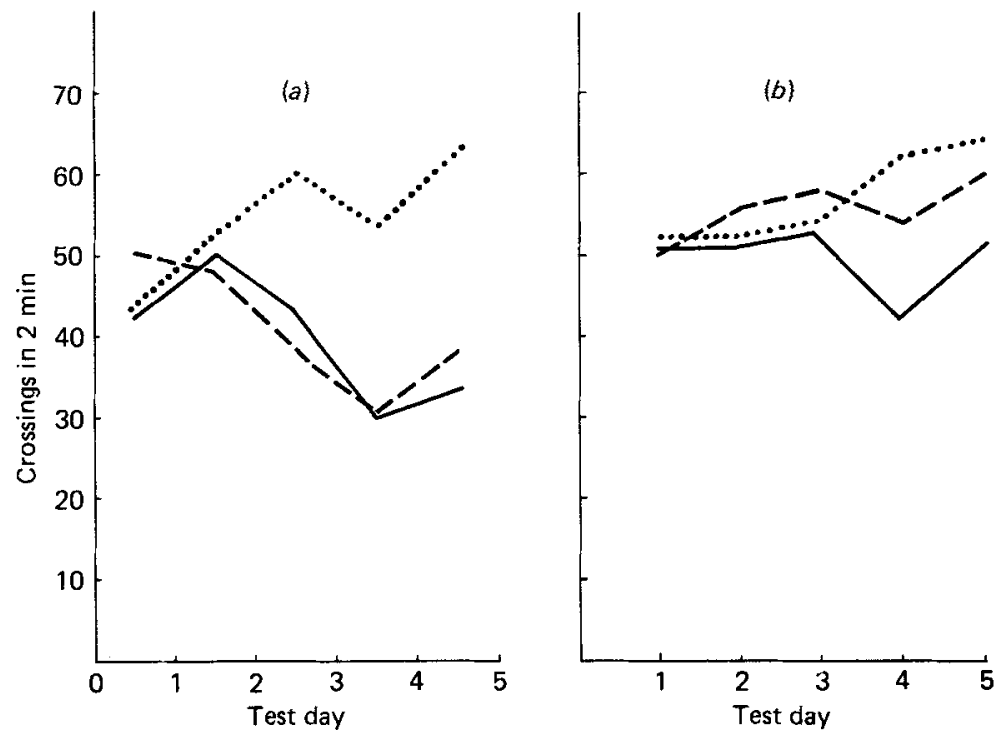

Fig. 4. Ambulation in 2 min open field tests on five consecutive days in $(a)$ male and (b) female rats from three treatment groups for six rats per group. ( - ), Group 1, controls (eight pups per litter); (---), group 2, food deprived, fostered; (...), group 3, food deprived, cooled.

\section{'Open field test'}

In control and fostered males, total ambulation decreased over test days whereas the score increased in previously cooled males (Fig. 4). The effect of treatment was significant (ANOVA: $F 2,15=5.23 ; P<0.05)$, as was that of test days $(F 4,60=3.41 ; P<0.05$ ) and treatment-days interaction $(F 8,60=3.40 ; P<0.01)$. Females were more active than males $(F 1,30=7.51 ; P<0.01)$, but there was no significant effect attributable to either treatment or days. There were no significant differences in rearing, grooming or defaecation in either sex.

\section{DISCUSSION}

This experiment clearly illustrates how regulation of body temperature is gradually acquired by young rats and that the mother, as a source of heat and not only of food, is necessary for normal growth both in the neonatal phase and also later when the infant's ability to produce heat gradually matures. The total amount of weight gained was much greater in undernourished pups kept warm by a foster mother than in those which were allowed to cool. Regulation of body temperature in altricial species is a gradual process which, in the rat, is not complete until approximately day 50 (Adolph, 1957). During the first few days of life, infants are wholly dependent on the mother for heat (Priestnall, 1983). Indeed she is very sensitive to the temperature of the pups, leaving the nest when the pups get too hot and returning when ultrasonic calls alert her that they are getting cold (Croskerry et al. 1978). Newborn rats are, however, very resistant to a drop in body temperature, an adaptation which allows the young to survive in cool surroundings while the mother leaves the nest for feeding. The lower limit for survival gradually increases as the infant acquires control over its own body temperature, by reducing heat loss through insulation and increasing heat production through a rise in oxygen consumption/g body-wt and, later, shivering. The capacity for heat production matures more quickly than mechanisms for 
preventing heat loss. The ratio, maximum $\mathrm{O}_{2}$ consumption: resting $\mathrm{O}_{2}$ consumption in rats (8-20 d of age) in response to cold can be 2.5 times as high as in the adult (Adolph, 1957).

The pattern of weight gain differed depending on the temperature at which the rat pups were kept during food deprivation. The daily fluctuations were much greater in warm than in cold pups, insofar as they lost more weight during deprivation but regained even more on refeeding. The greater weight loss in warm pups can be explained by more energy expenditure due to a higher metabolic rate and increased activity. It is more difficult to explain why the cooled pups profited so little from refeeding, since they were immediately gathered into the nest by the mother and warmed. Perhaps their reduced vigour for sucking failed to stimulate maximum milk production (Drewett, 1983). Before $8 \mathrm{~d}$ of age, when body temperature was the same as that of the surroundings, the metabolic rate on cooling was so low that digestion was inhibited, as seen by the presence of milk in the stomach. The debilitating effects of cold became more serious between 8 and $16 \mathrm{~d}$ of age, when the infants managed to increase their temperature to $26^{\circ}$. Although the metabolic rate was high enough to support digestion (since milk disappeared) the effort to maintain body temperature even partially with very little food reserve (Taylor, 1960) was so great that the rate of weight loss was even higher than during the first $8 \mathrm{~d}$. Moreover, the weight regained on refeeding was even further reduced. The pups became so weak that finally they were no longer able to suck. The resultant severe starvation resulted in the death of seven out of twenty-four pups at $16 \mathrm{~d}$ of age.

It is remarkable how quickly the remaining pups were rehabilitated on being allowed ad $l i b$. feeding. There seemed to be no permanent damage to their digestive capacity nor to their ability to assimilate nutrients. Although they remained smaller, the differences between non-fostered, fostered and control groups were reduced and, at $100 \mathrm{~d}$ of age, all animals appeared healthy and active. The observation that maturity indices, especially vaginal opening, were more closely related to chronological age than body-weight is in agreement with earlier findings (Widdowson \& McCance, 1960; Widdowson et al. 1964; Swanson et al. 1983).

During the first $10 \mathrm{~d}$ of life, rats spend as much as $70 \%$ of sleep time in AS (Jouvet-Mounier et al. 1969; Gramsbergen et al. 1970; Mirmiran et al. 1981). Reduction of AS to about 10\% from the age of 1-3 weeks by chlorimipramine or clonidine resulted in a higher AS percentage in adult life as well as some behavioural disturbances (Mirmiran et al. 1981, 1983). Since cooling also reduces active sleep (Schmidek et al. 1972), as confirmed in the additional sleep controls, the virtual abolition of AS during alternate 24-h periods in the cooled rats of the present experiment could affect later sleep patterns and/or behaviour. Indeed the AS/TST was somewhat higher in cooled than in control rats after 5 days' rehabilitation. This may have been a rebound effect but may also be a sign of immaturity. Mirmiran et al (1981) showed a slight rebound after chlorimipramine-induced active sleep deprivation from days 8 to 22 .

Mirmiran et al. (1983) observed that male rats, deprived of AS in early life, showed an increase in open field ambulation over test days, in contrast to controls, who ambulated less. In the present experiment, ambulation increased over test days in the previously-cooled male rats, whereas it decreased in the other two groups. It is tempting to speculate that the present results may be a consequence of early AS deprivation due to cooling. Females of the present experiment ambulated more than males, supporting usual findings (Van de Poll et al. 1978), but there was no effect of early cooling. Mirmiran et al. (1983) did not test females.

The main conclusion from this experiment is that both undernutrition and cooling must be considered in evaluating the consequences of maternal separation in rats. Food-deprived pups, kept warm by a foster mother, were in all respects intermediate between control and 
cooled, underfed pups. Elwood (1983) reported that gerbils and other rodents grew and matured faster if the father, as well as the mother, were present. This may be due to the infants being kept warmer for longer periods since the father could stay in the nest while the mother was feeding. Such a mechanism could also account for Frankova's (1974) findings that the presence of an 'aunt' reduced some of the behavioural abnormalities in rats which were suckled by a protein-deficient mother, a listless animal who did not show much maternal care, and spent little time in the nest.

However, maternal deprivation can have deleterious consequences even if cooling is prevented. Hofer $(1973,1976)$ showed that pups placed in an incubator had decreased cardiac and respiratory rates and also less AS. Young of species which are more mature and already able to keep up their body temperature at birth may react differently to undernutrition with or without separation from the mother. In addition to its direct effects, cooling increases the severity of undernutrition and has many other side effects such as sensory deprivation and AS reduction, which may affect brain and behavioural development. Finally, the large weight fluctuations during alternate periods of feeding and starvation suggest that shorter and more frequent episodes might be a better strategy for studying undernutrition.

\section{REFERENCES}

Adolph, E. F. (1957). Quarterly Review of Biology 32, 89-137.

Croskerry, P. G., Smith, G. K. \& Leon, M. (1978). Nature 273, 299-300.

Drewett, R. F. (1983). In Parental Behaviour in Rodents, pp. 181-204 [R. W. Elwood, editor]. Chichester: John Wiley.

Elwood, R. W. (1983). In Parental Behaviour in Rodents, pp. 235-258 [R. W. Elwood, editor]. Chichester: John Wiley.

Frankova, S. (1974). In Early Malnutrition and Mental Development, pp 202-209 [J. Cravioto, L. Hambraeus and B. Vahlquist, editors]. Stockholm: Swedish Nutrition Foundation.

Gramsbergen, A., Schwartze, P. \& Prechtl, H. F. R. (1970). Developmental Psychobiology 3, $267-280$.

Hofer, M. A. (1973). Physiology and Behaviour 10, 423-427.

Hofer, M. A. (1976). Developmental Psychobiology 9, 189-205.

Jouvet-Mounier, D., Astic, L. \& Lacote, D. (1969). Developmental Psychobiology 2, $216-239$.

Kennedy, G. D. (1957). Journal of Endocrinology 16, 9-17.

Lynch, A. (1976). Developmental Psychobiology 9, 39-48.

Mirmiran, M., Scholtens, J., Van de Poll, N. E., Uylings, H. B. M., Van de Gugten, J. \& Boer, G. J. (1983). Developmental Brain Research 7, 277-286.

Mirmiran, M., Van de Poll, N., Corner, M., Van Oyen, H. \& Bour, H. (1981). Brain Research 204, $129-146$.

Nowosielski-Slepowron, B. J. A. \& Park, A. W. (1974). Acta Morphological Neerlandica Scandinavica 12, $299-316$. Park, A. W. \& Nowosielski-Slepowron, B. J. A. (1971). Acta Anatomica 79, 15-26.

Plaut, S. M. (1970). Developmental Psychobiology 3, 157-167.

Priestnall, R. (1983). In Parental Behaviour in Rodents, pp. 67-94 [R. W. Elwood, editor]. Chichester: John Wiley. Rosenblatt, J. S. (1967). Science 156, 1512-1514.

Schmidek, W. R., Hoshino, K., Schmidek, K. \& Timo-Iaria, C. (1972). Physiology and Behaviour 8, $363-371$.

Slob, A. K., Snow, C. E. \& De Natris-Mathos, E. (1973). Developmental Psychobiology 6, 177-186.

Smart, J. L. (1983). In Parental Behaviour in Rodents, pp. 205-234 [R. W. Elwood, editor]. Chichester: John Wiley.

Smart, J. L. \& Preece, J. (1973). Animal Behaviour 21, 613-619.

Swanson, H. H., McConnell, P., Uylings, H. B. M., Van Oyen, H. G. \& Van de Poll, N. E. (1983). Behavioural Processes 8, 1-20.

Taylor, P. M. (1960). Journal of Physiology 154, 153-168.

Van de Poll, N. E., De Bruin, J. P. C., Van Dis, H. \& Van Oyen, H. G. (1978). In Maturation of the Nervous System; Progress in Brain Research, vol. 48, pp, 309-325 [M. A. Corner, B. Baker, N. E. Van de Poll, D. F. Swaab and H. B. M. Uylings, editors]. Amsterdam: Elsevier/North Holland.

Widdowson, E. M. \& Kennedy, G. C. (1962). Proceedings of the Royal Society B156, 96-108.

Widdowson, E. M. \& McCance, R. A. (1960). Proceedings of the Royal Society B152, 188-206.

Widdowson, E. M., Mavor, W. O. \& McCance, R. A. (1964). Journal of Endocrinology 29, $119-126$. 